carbon dioxide produced is estimated. The rate of air passing through is regulated by needle valves.

We have used this apparatus for studying nitrification and transformation of glucose in soil samples. When a glucose solution is passed through, the decrease in glucose concentration can be estimated as well as the production of carbon dioxide and the formation of volatile acids. We found that the formation of carbon dioxide and the volatile acids (related to the amount of glucose utilized) by the soil microflora is lower in the presence of nitrate than when a glucose solution containing no source of nitrogen is used. Only acetic acid could be detected by means of paper chromatography. The results show that under certain conditions an equilibrium state is established in the soil.

The method has principles in common with the method of heterogeneous continuous-flow cultivation of micro-organisms using a solid carrier. Similarly, as with continuous cultivations, it is possible also in our case to supply the soil continually with substrate at a considerably lower concentration than with other current methods. However, it is possible to prevent the exhaustion of the substrate and to ensure a sufficient amount of nutrients in the soil. Thus the soil population can be maintained at a certain level determined by the rate of flow and by the concentra tion of essential nutrients. As the controlling growth factor, an energy source, a nitrogen source and the like can function. It is also possible to follow the transformation of various substrates one after the other and to influence the composition of the soil microbial association.

Detailed results are to be published elsewhere.

$$
\begin{aligned}
& \text { J. Macura } \\
& \text { I. Málek }
\end{aligned}
$$

Department of Microbiology, Institute of Biology,

Czechoslovak Academy of Sciences,

Prague 6.

Nov. 19.

${ }^{1}$ Lees, H., and Quastel, J. H., Chem. and Indust., 26, 238 (1944).

2 Lees, H., Plant and Soil, 1, 221 (1949).

${ }^{3}$ Málek, I.. Cas. lék. ces., 82, 576 (1943).

${ }^{4}$ Monod, J., Ann. Inst. Pasteur, 79, 390 (1950).

Sovick, A., and Szillard, L., Science, 112, 715 (1950).

"Continuous Cultivation of Microorganisms" (Cz. Acad. Sci., Prague 1958).

7 Vávra, J., Cs, biologie, \%, 466 (1958)

${ }^{8}$ Audus, L. J., Nature, 158, 419 (1946)

\section{Thermal Annealing of Chemical Radiation Damage}

At present the only observations on the thermal annealing of chemical radiation damage appear to be some measurements on potassium nitrate reported in $1955^{1}$. These measurements did not include isothermal kinetic studies, nor do they appear to exclude some possible alternative explanations of the observations. We have made measurements on the isothermal annealing of radiolysed lead nitrate and subsidiary experiments which seem to exclude any alternative explanation of the results. The experiments were conducted on a sample of vacuum-dried lead nitrate crystals sieved to botween 80 and 100 mesh. The crystals were irradiated to a dose of about $50 \mathrm{Mr}$. with $2 \mathrm{MeV}$. electrons from a Van de Graaff accelerator. A typical plot of the disappearance of the nitrite, produced by the irradiation, upon thermal annealing of the crystals is shown in Fig. 1.

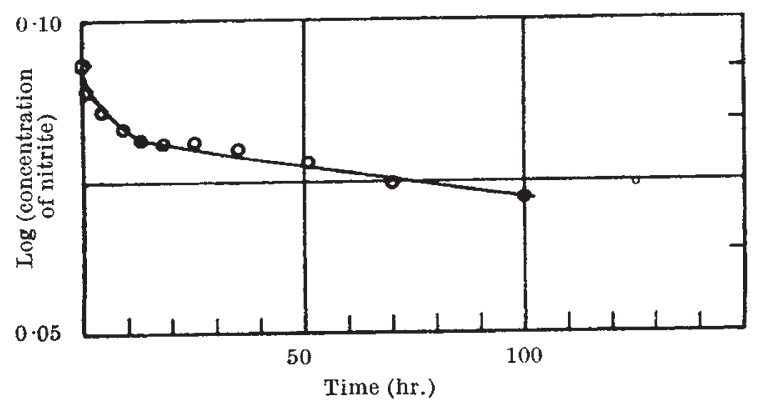

Fig. 1. Thermal annealing of irradiated lead nitrate

The possibility that the observed effect arose from aerial oxidation was excluded by showing that virtually the same annealing occurred whether the crystals were heated in air or in vacuo. Another possibility that the disappearance of the nitrite was due to thermal decomposition of the lead nitrite, to give lead oxide and oxides of nitrogen, was excluded by showing that in synthetic mixed crystals of lead nitrate and nitrite, prepared by crystallization from a solution of the nitrate and nitrite, the concentration of nitrite was unchanged after heating for $65 \mathrm{hr}$. at $150^{\circ} \mathrm{C}$. in vacuo. It is concluded that the effects observed represent a true annealing of the chemical radiation damage. Similar experiments have shown that photolysed lead nitrate crystals can be annealed in the same way.

Such an effect is implied by the model for the radiolysis recently proposed by Cunningham and $\mathrm{Heal}^{2}$, but the kinetic pattern of the recombination is more complex than the unimolecular recombination indicated by this model. A detailed account of the results and an analysis of the kinetic aspects will appear shortly.

We are indebted to Tube Investments Research Laboratory, Hinxton Hall, Cambridge, for carrying out the irradiations.

\section{A. G. Maddock}

S. R. MOHANTY

The Radiochemical Laboratory,

University Chemical Laboratory,

Lensfield Road, Cambridge.

Oct. 25.

${ }^{1}$ Proskurnin, M. A., Orekhov, V. D., arid Barelck, E. V., Conf. Acad. Sci. U.S.S.R. on Peaceful Uses of Atomic Lnergy, Session of Dn. of Chem. Sci., 41 (1955).

${ }^{2}$ Cunningham, J., and Heal, H. G., Trans. Faraday Soc., 54, 1355 (1958).

\section{Polymorphic Transitions in Anhydrous Sodium Sulphate}

Kreidl and Simon have noted ${ }^{1}$ that form $V$, the stable low-temperature form of sodium sulphate, was transformed, when in contact with water, directly and reversibly to the hexagonal high-temperature form I. This occurred at a temperature of about $238^{\circ} \mathrm{C}$

We have observed an irreversible change from form $\mathrm{V}$ to form $\mathrm{I}$ in the dry state at a temperature of only $176^{\circ} \mathrm{C}$. (approximately). The observation was made in a high-temperature $\mathrm{X}$-ray diffraction camera with the sample loosely packed in an openended quartz tube. Fig. I shows diffraction patterns recorded at temperatures of $161^{\circ}, 176^{\circ}, 180^{\circ} \mathrm{C}$., and room temperature, in that order. These show respectively form V, a mixture of forms $\mathrm{V}$ and $\mathrm{I}$, form I and form III. 